peratures, below the transition where fractures are 100 pet brittle.

2-Within the transition range, the increased deformation results in strain markings which branch out from the notch, and a larger strained area at the bottom of the specimen due to compressive stresses is obtained. The correspondingly smaller elastically stressed portion is characteristic of partially "brittle" fractures within the transition energy range.

3 -Above the transition temperature, the entire region from the bottom of the specimen to the notch, and a broad area following the contour of the notch, shows plastic flow. The 100 pct "ductile" fractures are characteristic of this energy level.

\section{Acknowledgment}

The author acknowledges his indebtedness to
M. Baeyertz, who conceived and initiated this study, and to Walter Craig, who supervised and encouraged the experimental work. Thanks are due to J. P. Sheehan for assistance, and to M. Hansen and the Armour Research Foundation for permission to publish these results.

\section{References}

${ }^{1}$ A. Fry: Stahl und Eisen (1921) 41, p. 1093.

2 J. D. Jevon: Journal Iron and Steel Inst. (1925) 111, pp. 191-204

${ }^{3}$ W. J. Harris, Jr., J. A. Rinebolt, and R. Raring: Welding Journal (September 1951) p. 417-S.

${ }^{4}$ Metals Handbook (1948) p. 391. Cleveland. A.S.M.

${ }^{5}$ M. Gensamer: Strength of Metals Under Combined Stresses (1941) pp. 18-20. Cleveland. A.S.M.

${ }^{6}$ M. Baeyertz, W. F. Craig, Jr., and E. S. Bumps: Trans. AIME (1949) 185, pp. 481-490; JourNAL of Metals (August 1949).

Technical Note

\title{
Diffusion of Silicon in Iron
}

\author{
by W. Batz, H. W. Mead, and C. E. Birchenall
}

A $\mathrm{T}$ temperatures between $1095^{\circ}$ and $1347^{\circ} \mathrm{C}, 13$ runs have been made on the diffusion of silicon in iron. In two of the runs the couple compositions were entirely within the $\gamma$ loop of the Fe-Si system; the base alloys contained 0.0 and 1.0 wt pct Si. The other runs in which the couples consisted of a 2.3 wt pct Si alloy welded to a 3.7 pct $\mathrm{Si}$ alloy were $\alpha$ phase throughout. The alloys were made by melting electrolytic iron and commercially pure silicon. Trace impurities were not determined.

The butt welded couples were diffused in an inert atmosphere of argon or hydrogen. After cooling, cuts of two mils or greater thickness were machined parallel to the weld interface. The chips were analyzed for silicon. When the concentration and distance data were examined on the conventional probability plot, ${ }^{1}$ no marked variation of the diffusion coefficient with concentration was indicated over the narrow composition ranges employed. Therefore, a single diffusion coefficient is recorded for each run in Table I. The temperatures and atmospheres of the diffusion anneal are listed along with the compositions of the base alloys.

For $\alpha$ iron the silicon diffusion coefficient is given by the equation:

$$
D=0.44 e^{-48,000 / R T}
$$

where $R$ is the gas constant and $T$, the absolute temperature. However, since the scatter in the data is fairly large, the activation energy may be in error by as much as 6000 cal per g-atom.

The two $\gamma$ iron points do not permit estimation of the activation energy with any reasonable certainty. They do indicate that the coefficients reported by Smithells ${ }^{2}$ and Jost, ${ }^{3}$ based on the work of Fry, ${ }^{4}$ are much too high.

Although very dilute solutions in iron of manganese, ${ }^{5}$ nickel, ${ }^{6}$ cobalt, $^{7}$ and molybdenum ${ }^{8}$ give dif-

W. BATZ, formerly Research Assistant, Metals Research Laboratory, Carnegie Institute of Technology, is now with the Research Laboratories, Jones \& Laughlin Steel Corp., Pittsburgh, H. W. MEAD, Junior Member AIME, is Research Associate, Metals Research Laboratory, Carnegie Institute of Technology, Pittsburgh, and C. E. BIRCHENALL, Junior Member AIME, formerly Member of Staff, Metals Research Laboratory, is now Assistant Professor of Chemistry, Princeton University, Princeton, N. J.

TN 123E. Manuscript, June 27, 1952.
Table I. Diffusion Coefficients of Silicon in $\alpha$ and $\gamma$ Iron

\begin{tabular}{clcc}
\hline $\begin{array}{c}\text { Composition } \\
\text { Range, } \\
\text { Wt Pct }\end{array}$ & $\begin{array}{c}\text { Annealing } \\
\text { Atmosphere }\end{array}$ & $\begin{array}{c}\text { Diffusion } \\
\text { Tempera- } \\
\text { ture, }{ }^{\circ}\end{array}$ & $\begin{array}{c}\text { DC } \\
\text { Coefficient, } \\
\text { Sq Cm } \\
\text { per Sec }\end{array}$ \\
\hline $0.0-1.0$ & Hydrogen & 1206 & $4.0 \times 10^{-10}$ \\
$0.0-1.0$ & Hydrogen & 1293 & $1.7 \times 10^{-9}$ \\
$2.3-3.7$ & Argon & 1095 & $1.5 \times 10^{-8}$ \\
$2.3-3.7$ & Argon & 1194 & $2.4 \times 10^{-8}$ \\
$2.3-3.7$ & Argon & 1201 & $4.2 \times 10^{-8}$ \\
$2.3-3.7$ & Argon & 1202 & $3.2 \times 10-8$ \\
$2.3-3.7$ & Hydrogen & 1249 & $5.0 \times 10^{-8}$ \\
$2.3-3.7$ & Hydrogen & 1255 & $5.7 \times 10^{-8}$ \\
$2.3-3.7$ & Hydrogen & 1284 & $1.3 \times 10^{-7}$ \\
$2.3-3.7$ & Hydrogen & 1300 & $9.0 \times 10^{-8}$ \\
$2.3-3.7$ & Hydrogen & 1306 & $1.1 \times 10^{-7}$ \\
$2.3-3.7$ & Hydrogen & 1344 & $1.2 \times 10^{-7}$ \\
$2.3-3.7$ & Hydrogen & 1347 & $1.3 \times 10^{-7}$ \\
\hline
\end{tabular}

fusion coefficients quite close to those obtained for self-diffusion in iron, the silicon values are considerably higher, though of the same order of magnitude. This seems to be consistent with the fact that the silicon atom is the only one of those listed here which is appreciably smaller than iron.

The authors are grateful to the Office of Naval Research for their support of this work under Contract N6ori-47, Task Order IV, Project NR 031-184, to J. K. Stanley and the Westinghouse Research Laboratories for the silicon alloys used, to several steel companies for the silicon analyses, and to C. Wells, of the Metals Research Laboratory, Carnegie Institute of Technology, for numerous suggestions during the course of the work.

\section{References}

${ }^{1}$ C. Wells: Atom Movements (1951) Chapter 2. A.S.M.

${ }^{2}$ C. J. Smithells: Metals Reference Book (1949) p. 405. Interscience. Pub. Co.

${ }^{3}$ W. Jost: Diffusion (1952) p. 223. Academic Press.

${ }^{4}$ A. Fry: Stahl und Eisen (1923) 43, p. 1039.

"C. Wells and R. F. Mehl: Trans. AIME (1941) 145, p. 315 .

${ }^{\circ}$ C. Wells and R. F. Mehl: Trans. AIME (1941) 145, p. 329 .

${ }^{7}$ M. F. Hawkes and R. F. Mehl: Trans. AIME (1947)

172, p. 467; Metals Technology (August 1947).

${ }^{8}$ J. L. Ham: Trans. A.S.M. (1945) 35, p. 331. 